\title{
OS SENTIDOS DA INTERDISCIPLINARIDADE ATRAVÉS DOS OLHARES DE LICENCIANDAS EM CIÊNCIAS DA NATUREZA: UMA EXPERIÊNCIA NO ESTÁGIO
}

\section{THE SENSES OF INTERDISCIPLINARITY THROUGH THE VIEWS OF THE UNDERGRADUATES STUDENTS OF THE NATURAL SCIENCES: AN EXPERIENCE IN THE INTERNSHIP}

\author{
Gisele Soares Lemos Shaw ${ }^{1}$, João Batista Teixeira da Rocha ${ }^{2}$ \\ ${ }^{1}$ Universidade Federal do Vale do São Francisco e Universidade Federal do Rio Grande do Sul, \\ giseleshaw@hotmail.com \\ ${ }^{2}$ Universidade Federal de Santa Maria, jbtrocha@yahoo.com.br
}

\begin{abstract}
RESUMO
Apesar dos incentivos legais e da literatura especializada à implementação da interdisciplinaridade no ensino, falta formação de professores para esse tipo de trabalho. Isso se aplica principalmente junto a professores da área de ciências da natureza, que precisam saber integrar conhecimentos de diferentes disciplinas, principalmente de Biologia, Química e Física. Nesse artigo, apresentamos a importância da formação docente para o exercício do trabalho interdisciplinar e acompanhamos os sentidos da interdisciplinaridade e as práticas de quatro licenciandas em Ciências da Natureza durante seu processo formativo. Os dados das participantes foram coletados por meio dos relatos de suas memórias sobre o ensino, de discussões que ocorreram em aulas de estágio, da exame de seus relatórios do primeiro estágio e através de entrevistas individuais. Para análise desses dados foi utilizada a Análise Textual Discursiva. Apontamos que três participantes apresentaram compreender a importância da interdisciplinaridade, pensaram ter realizado essa prática, mas não o fizeram de fato. A quarta licencianda conseguiu integrar interdisciplinarmente conteúdos das disciplinas Biologia, Matemática e Língua Portuguesa.
\end{abstract}

Palavras-chave: Estágio; Formação de Professores; Interdisciplinaridade.

\begin{abstract}
Despite the legal incentives and specialized literature to the implementation of interdisciplinarity in teaching, there is a lack of teacher training for this kind of work. This mainly applies to teachers in the natural sciences area, who need to be able to integrate knowledge from different disciplines, mainly those of Biology, Chemistry and Physics. In this paper, we present the importance of teacher training for the exercise of interdisciplinary work and follow the senses of interdisciplinarity and the practices of four undergraduates' students of the Natural Sciences during their formative process. We collected data of the participants through reports of their memories about teaching, discussions that took place in internship classes, analysis of their first-stage reports, and through individual interviews. We used the Discursive Textual Analysis to analyze these data. We pointed out that three participants presented an understanding of the importance of interdisciplinary; they thought they had done this, but did not actually do it. The fourth participant was able to integrate interdisciplinary knowledge of Biology, Mathematics and Portuguese Language.
\end{abstract}

Key words: Internship; Teacher training; Interdisciplinarity. 


\section{INTRODUÇÃO}

A implementação da interdisciplinaridade no ensino tem sido incentivada tanto pela literatura especializada na área (AZEVEDO, 2014; FAZENDA, 2009a, 2009b, 2012a, 2012b; PIATTI et al, 2008; MACHADO et al, 2014; PRESTES e SILVA, 2009, ROSA et al, 2003) quanto por documentos oficiais governamentais (BRASIL, 2000, 2012, 2013). Porém, uma das maiores dificuldades no desenvolvimento de práticas interdisciplinares nas escolas tem sido a falta de formação dos professores para esse trabalho (FAZENDA, 2011; PEDROMO JUNIOR et al, 2015; THIESEN, 2008). Esse fato se aplica especialmente junto a professores atuantes na área de ciências da natureza do Ensino Fundamental, que necessitam integrar conhecimentos de diferentes disciplinas, principalmente da Biologia, da Física e da Química. Assim, esses professores, bem como os professores de outras matérias, precisam adquirir conhecimentos necessários à realização do trabalho interdisciplinar na escola, tanto para obter conhecimentos dos conteúdos da Física, da Química e da Biologia quanto para adquirir conhecimentos pedagógicos dos conteúdos e conhecimentos curriculares (SHULMAN, 1986).

Esse desafio de formação de professores para o exercício da interdisciplinaridade é enfrentado por docentes formadores e licenciandos do Curso de Licenciatura em Ciências da Natureza da Universidade Federal do Vale do São Francisco (UNIVASF). Esse curso foi criado no município de Senhor do Bonfim, Bahia, no ano de 2009, visando a formação de professores de Ciências para atuar nos anos finais do Ensino Fundamental e em espaços não formais de ensino. Para isso, seu estágio curricular busca a articulação teoria-prática docente e a superação da fragmentação do saber, tendo como eixos a investigação, a intervenção e a interdisciplinaridade. De acordo com o Projeto Pedagógico do Curso o currículo tem como eixo integrador a "Educação em ciências, no intuito de proporcionar a interdisciplinaridade entre as diferentes áreas (Química, Física, Biologia e Matemática), que compõem as ciências da natureza" (UNIVERSIDADE FEDERAL DO VALE DO SÃO FRANCISCO, 2012, p. 31). Então, foi pensada uma natureza interdisciplinar como base da formação desses futuros professores de Ciências, tendo em vista a integração de conhecimentos de diversas áreas do saber e a construção de uma identidade profissional docente interdisciplinar. 
Para Fazenda (2012a), as investigações que tratam de questões relativas a essa referida identidade interdisciplinar nos mostram que não devemos somente explicar as causas das ações e representações dos indivíduos em determinadas situações de vida, os porquês de suas ações, mas sim compreendê-las a partir da forma que ocorreram, ou seja, acompanhar o processo. Diante isso, buscando contribuir com discussões acerca da formação docente interdisciplinar, apresentaremos alguns entendimentos dos sentidos da interdisciplinaridade e também do ensinar ciências, construídos por quatro licenciandas em Ciências da Natureza da UNIVASF em processo de estágio. Os dados coletados junto às licenciandas foram obtidos durante os anos de 2013 e 2014, por meio dos relatos de suas memórias sobre o ensino, discussões que ocorreram em aulas de estágio, análise de seus relatórios do primeiro estágio e através de entrevistas individuais realizadas junto às licenciandas participantes ao final desse estágio. Para análise desses dados foi utilizada a análise textual discursiva (MORAES, 2003; MORAES e GALIAZZI, 2006).

A seguir refletiremos acerca da interdisciplinaridade no ensino, o que nos ajudou a pensar e interpretar os sentidos atribuídos pelas licenciandas a essas questões. Também descreveremos os caminhos da pesquisa, apresentaremos resultados e discussões, além de algumas considerações finais.

\section{REFLEXÕES SOBRE A INTERDISCIPLINARIDADE NO ENSINO}

Muito se discute no meio acadêmico e no ambiente escolar acerca da viabilização de práticas interdisciplinares no ensino. Para Spelt et al (2009) a interdisciplinaridade ajuda na resolução de problemas complexos insurgentes no cotidiano e, por isso, cada vez mais são demandados cursos de ensino superior que formem pessoas capazes de trabalhar interdisciplinarmente. Entretanto, existem muitas dúvidas acerca de qual seja a melhor conceitualização para a interdisciplinaridade no ensino e sobre como operacionalizá-la: esses desafios são impostos aos professores e futuros professores que muitas vezes não sabem para quê o fazem, nem como fazê-lo.

De acordo com Newelll e Green (1982), apesar da existência de muitos programas interdisciplinares no ensino superior, ainda há grande ceticismo no meio acadêmico quanto aos mesmos. Isso se dá, segundo os autores, em parte por problemas de definição do que seja a interdisciplinaridade, pois o termo "estudos interdisciplinares" tem sido empregado por quaisquer cursos que não se encaixem nos padrões do que seja disciplinar - o que tem levado os programas interdisciplinares à 
banalização e ao descrédito. Além disso, Newell e Green (1982) citam a inexistência de parâmetros consensuados para avaliar esse tipo de programa.

Para Fazenda (2011), os preconceitos em relação à adesão da interdisciplinaridade no ensino são associados ao temor de que ao se instaurar uma metodologia interdisciplinar se perca a unidade particular de cada disciplina. Isso se dá, segunda a autora, tanto por conta do desconhecimento do real significado do projeto interdisciplinar, quanto pela falta de formação específica para isso, além da própria acomodação pessoal e coletiva. Fazenda (2011) e Japiassu (1976) destacam que o desenvolvimento do ensino interdisciplinar parte da atitude de quem deseja fazê-lo, de sua predisposição a isso, o que não desconsidera a importância do trabalho coletivo.

Em decorrência da existência de interpretações equivocadas acerca da interdisciplinaridade, tanto Japiassu (1976) quanto Fazenda (2011) trazem o conceito de Jantsch (1973) sobre o que seja interdisciplinaridade, comparando-o aos conceitos de multidisciplinaridade, pluridisciplinaridade e transdisciplinaridade, de modo a nortear essa compreensão. Para Jantsch (1973 apud FAZENDA, 2011):

\footnotetext{
Multidisciplinaridade - gama de disciplinas que se propõem simultaneamente, mas sem fazer aparecer as relações que possam existir entre elas; destina-se a um sistema de um só nível e de objetivos múltiplos, mas sem nenhuma cooperação.
}

Pluridisciplinaridade - justaposição de diversas disciplinas, situadas geralmente no mesmo nível hierárquico e agrupadas de modo que façam aparecer as relações existentes entre elas; destina-se a um tipo de sistema de um só nível e de objetivos múltiplos, onde existe cooperação, mas não coordenação.

Interdisciplinaridade - destina-se a um sistema de dois níveis e de objetivos múltiplos onde há coordenação procedendo do nível superior.

Transdisciplinaridade - coordenação de todas as disciplinas e interdisciplinas do sistema de ensino inovado, sobre a base de uma axiomática geral, destina-se a um sistema de nível e objetivos múltiplos — há coordenação com vistas a uma finalidade comum dos sistemas (p. 68).

Ainda há muita confusão, tanto no meio acadêmico quanto no meio escolar, principalmente entre os conceitos de interdisciplinaridade e multidisciplinaridade. Para Japiassu (1976) o que determina o empreendimento interdisciplinar é a capacidade de tomar empréstimo a outras disciplinas de certos instrumentos e técnicas metodológicas, esquemas conceituais e análises “(...) a fim de fazê-los integrarem e convergirem, depois de terem sido comparados e julgados" (JAPIASSU, 1976, p. 75). Segundo Spelt et al (2009) enquanto que a multidisciplinaridade é aditiva a interdisciplinaridade é 
integrativa ${ }^{1}$. Conforme Newell e Green (1982), por conta dessa confusão de conceitos, muitos cursos classificados como interdisciplinares são na verdade multidisciplinares os responsáveis, nesse caso, acreditam que a reunião de duas ou mais disciplinas, para tratar de um assunto dentro de um mesmo contexto, resulta em um trabalho interdisciplinar. Nesse caso, há a desconsideração da necessidade da integração disciplinar.

Spelt et al (2009) explicam que o trabalho interdisciplinar no ensino superior visa o desenvolvimento do pensamento interdisciplinar que é "(...) as the capacity to integrate knowledge of two or more disciplines to produce a cognitive advancement in ways that would have been impossible or unlikely through single disciplinary means", (p. 365). Esses autores caracterizam o pensamento interdisciplinar como algo complexo e constituído por certo número de subcompetências e afirmam que ele não ocorre espontaneamente. Além disso, para que o pensamento interdisciplinar seja desenvolvido também são necessárias condições específicas típicas. As subcompetências e condições necessárias à aquisição do pensamento interdisciplinar são: subcompetências concernentes ao pensar interdisciplinar (ter conhecimentos das disciplinas, de paradigmas e da interdisciplinaridade, além de habilidades de comunicação de ordem superior); condições relativas a características pessoais do estudante (curiosidade, respeito, abertura, paciência, diligência, auto-regulação) e condições referentes a experiências anteriores do mesmo; condições referentes ao ambiente de aprendizagem currículo, professor, pedagogia, avaliação; e condições relativas ao processo de aprendizagem - padrões e atividades de aprendizagem (SPELT et al, 2009).

Newell e Green (1982) apresentaram sua experiência interdisciplinar bemsucedida no Programa da Faculdade Western, na Universidade de Miami, Estados Unidos da América. Esse programa, criado desde 1970, é organizado em torno de quatro anos de seminários interdisciplinares da equipe de ensino na área de humanas, ciências sociais e ciências naturais que trabalham onze disciplinas. Esses autores apontam que os alunos do Programa da Faculdade Western tendem a: procurar argumentos de forma

\footnotetext{
${ }^{1}$ Fazenda (2011) explica que o termo integração compreende uma etapa anterior à interdisciplinaridade “(...) em que se iniciaria um relacionamento, um estudo, uma exegese dos conhecimentos e fatos a serem posteriormente interados" (p. 83).

${ }^{2}$ Tradução proposta pela autora: "a capacidade de integrar os conhecimentos e modos de pensar de duas ou mais disciplinas ou da experiência estabelecida em áreas para produzir um avanço cognitivo, tal como explicar um fenômeno, resolver um problema, ou criar maneiras de fazer que seriam impossíveis ou improváveis, através de um único caminho disciplinar".
} 
mais crítica, mostrar-se mais receptivos a novas ideias, estar mais propensos a identificar preconceitos e vieses ideológicos, ficar atentos a questões éticas em investigações realizadas e desenvolver mais tolerância à ambiguidade.

A experiência da Faculdade Western nos leva a evidenciar a importância de trabalhar a interdisciplinaridade nos cursos de formação de professores, para que estes saibam enfrentar as dificuldades do cotidiano escolar. Além disso, observamos a importância da vivência de práticas interdisciplinares ou potencialmente interdisciplinares nas licenciaturas: "Muito mais que acreditar que se aprende a Interdisciplinaridade praticando-a ou vivendo-a, estudos mostram que uma sólida formação à Interdisciplinaridade encontra-se extremamente acoplada às dimensões advindas de sua prática em situação real e contextualizada" (FAZENDA, 2011, p. 23).

Enfim, apesar das vantagens relativas ao desenvolvimento da interdisciplinaridade, tanto na escola quanto na academia, é preciso conhecer bem sua definição e desenvolver conhecimentos necessários a isso.

\section{CAMINHOS DA PESQUISA}

A investigação, que resultou nesse artigo, teve natureza qualitativa, que segundo Bogdan e Biklen (1994) é voltada aos processos e envolve a investigação do fenômeno em sua complexidade. Investigamos concepções e práticas potencialmente interdisciplinares de licenciandos em Ciências da Natureza da UNIVASF. Nesse artigo enfatizamos as concepções de quatro desses licenciandos, apesar de trazer suas práticas, ainda que de forma não detalhada.

Os sentidos atribuídos pelos sujeitos participantes da pesquisa acerca da interdisciplinaridade foram analisados segundo o paradigma fenomenológico, pois partiu da visão de mundo dessas pessoas. Para Moraes (2003), isso implica “(...) um esforço de colocar entre parênteses as próprias ideias e teorias e exercitar uma leitura a partir da perspectiva do outro" (p. 193). Dentre as quatro licenciandas investigadas, uma também é professora da rede municipal de ensino de Senhor do Bonfim, Bahia.

A coleta de dados que propiciou a apreensão desses sentidos foi realizada por meio de anotações feitas em duas aulas da disciplina Docência em Ciências: cultura escolar e cultura científica, da qual participaram as quatro licenciandas em questão. Nessas aulas, realizadas em outubro de 2013, foram compartilhadas memórias de ensino pelas licenciandos, além de suas perspectivas de futuro na docência em Ciências. Também foram coletados dados de duas aulas da disciplina Estágio, que aconteceram 
no semestre seguinte, da qual participaram as estudantes envolvidas na pesquisa. Essas aulas de estágio foram videogravadas e transcritas. Além disso, também foram analisados seus relatórios de estágio e foram realizadas entrevistas individuais com cada uma delas.

As aulas da Disciplina Estágio que foram videogravadas, ocorreram nos dias nove e onze de março do ano de 2014. Nessas aulas, as licenciandas apresentaram mapas conceituais explicando as relações entre três assuntos que haviam sido discutidos em classe - os tipos de estágio na visão de Selma Garrido Pimenta, os saberes da docência com base em Maurice Tardif e a função social do ensino por Antoni Zabala (PIMENTA, 2014; TARDIF, 2007; ZABALA, 1998.); relacionando essas ideias com a experiência que estava sendo iniciada no estágio.

Cada uma das entrevistas, realizada de maneira semiestruturada, também foi videogravada e transcrita. Inicialmente, foram sondadas informações básicas, pessoais e profissionais de cada entrevistada: nome completo, data de nascimento, formação e experiência com a docência. Posteriormente, as questões que nortearam as entrevistas foram pautadas em: seu entendimento sobre temas transversais e transdisciplinaridade, sua concepção de interdisciplinaridade, acerca da possibilidade de desenvolver a interdisciplinaridade no ensino de ciências, se conseguiu desenvolver práticas interdisciplinares no estágio, como foi sua experiência no estágio, se a experiência no estágio mudou de alguma forma sua concepção de ensinar ciências ou sua percepção sobre a interdisciplinaridade.

O estágio das licenciandas foi pautado em momentos na escola e momentos na universidade, totalizando 140 horas de carga horária. Na universidade foram realizadas leituras, reflexões, discussões de texto, compartilhamento da experiência de estágio, planejamento, discussão e replanejamento de atividades do estágio, compartilhamento de dúvidas, de inseguranças e de concretizações no estágio, além da realização de oficinas pedagógicas potencialmente interdisciplinares, junto aos alunos do estágio.

Nas escolas, as licenciandas realizaram sondagem do ambiente escolar e de duas turmas dos anos finais do ensino fundamental junto às quais iriam estagiar, com entrevista, observação, coparticipação, depois, regência em aulas da disciplina Ciências. A proposta era que cada dupla de licenciandas elaborasse um projeto de trabalho interdisciplinar para o estágio, após conhecer a escola e as turmas, buscando trabalhar interesses e necessidades dos estudantes, envolvendo conteúdos de Ciências (previstos no programa do professor de Ciências da escola) e temas transversais. Para esse intento, 
foi criada, na parte operacional do projeto de trabalho, uma sequência didática envolvendo práticas interdisciplinares. Foi sugerido que essa sequência fosse aplicada junto a uma das turmas de estágio e, depois dos resultados serem aferidos, refletidos e discutidos na universidade, a sequência deveria ser replanejada e aplicada com a segunda turma do estágio.

Além do suporte dos professores de estágio da universidade (uma docente com formação em Pedagogia e mestrado em Ensino, História e Filosofia das Ciências e outro docente, com Licenciatura em Química e doutorado em Química) alguns estagiários também discutiram os conteúdos a ser trabalhados no estágio com acadêmicos que lecionavam disciplinas envolvidas na sua sequência didática. Além disso, esses estagiários também tinham suporte dos professores de Ciências das escolas campo de estágio, que eram seus supervisores.

A pesquisa seguiu as normas prescritas pela Resolução no. 466/12 do Conselho Nacional de Saúde, que trata da Ética em Pesquisa com Seres Humanos. Foram resguardadas as identidades das licenciandas que autorizaram a coleta e utilização de seus dados.

Os dados foram analisados por meio da Análise Textual Discursiva (MORAES, 2003; MORAES E GALIAZZI, 2006). Seguindo essa abordagem, iniciamos o processo com a unitarização dos dados, fragmentando-os em unidades consideradas de maior relevância no estudo. Cada uma dessas unidades foi reescrita de modo a obter significado individualmente e a cada uma delas foi atribuído um sentido, que representa o primeiro esforço de categorização dos dados. Em seguida, foram observados os padrões entre as unidades de sentido, que foram categorizadas em: Concepção de Interdisciplinaridade e Resultados das Atividades Desenvolvidas. Depois, essas unidades foram codificadas por meio da utilização de letra inicial correspondente à fonte de dados de onde foi retirada a unidade - Relatório de estágio (R), aula na universidade (A) ou entrevista (E) - seguidas das categorias encontradas - Concepção de Interdisciplinaridade (CI) e Resultados das atividades desenvolvidas (R). Posteriormente, a intensa análise das unidades de sentido codificadas, articuladas às teorias que auxiliaram na interpretação das mesmas, resultou num metatexto, que representou o novo emergente a partir dos dados coletados. 


\section{RESULTADOS E DISCUSSÕES}

Denominamos as licenciandas por pseudônimos - Laura, Norma, Talita e Lara; de modo a preservar suas identidades. As duas primeiras licenciandas, Laura e Norma, estagiaram juntas, numa escola pública municipal. Talita estagiou também numa escola pública municipal e em dupla com outra colega, da qual não foram obtidos dados suficientes para a pesquisa. Já Lara decidiu estagiar individualmente, numa escola pública estadual. Como já era professora, Lara se sentiu à vontade em estagiar sem a parceria de outra colega de classe. No quadro 1 apresentamos algumas informações acerca dessas participantes e sua relação com a docência.

Quadro 1. Relação das licenciandas com a docência

\begin{tabular}{|c|c|c|c|c|}
\hline Licencianda & $\begin{array}{c}\text { Ano de } \\
\text { nascimento }\end{array}$ & Formação & $\begin{array}{l}\text { Experiência com } \\
\text { docência }\end{array}$ & $\begin{array}{l}\text { Período de } \\
\text { experiência } \\
\text { docente }\end{array}$ \\
\hline LAURA & 1994 & $\begin{array}{c}\text { Licencianda em } \\
\text { Ciências da } \\
\text { Natureza }\end{array}$ & $\begin{array}{c}\text { Monitora de leitura } \\
\text { do Programa Mais } \\
\text { Educação }{ }^{3}\end{array}$ & Um mês e meio \\
\hline NORMA & 1992 & $\begin{array}{c}\text { Licencianda em } \\
\text { Ciências da } \\
\text { Natureza }\end{array}$ & Não & Não se aplica \\
\hline TALITA & 1980 & $\begin{array}{c}\text { Licencianda em } \\
\text { Ciências da } \\
\text { Natureza }\end{array}$ & Catequista/PIBID 4 & $\begin{array}{c}\text { Catequista } \\
\text { durante a } \\
\text { adolescênciano } \\
\text { PIBID no ano } \\
\text { da entrevista } \\
\text { (2014) }\end{array}$ \\
\hline LARA & 1985 & $\begin{array}{c}\text { Ensino Médio } \\
\text { Formação Geral e } \\
\text { Magistério/ } \\
\text { Licencianda em } \\
\text { Ciências da } \\
\text { Natureza e em } \\
\text { Letras }\end{array}$ & $\begin{array}{c}\text { Professora da } \\
\text { terceira série do } \\
\text { Ensino } \\
\text { Fundamental } \\
\text { Professora da } \\
\text { Educação Infantil }\end{array}$ & $\begin{array}{c}\text { Na Educação } \\
\text { Fundamental } \\
\text { durante o } \\
\text { estágio no } \\
\text { curso de } \\
\text { Magistério/ } \\
\text { Atualmente } \\
\text { leciona na } \\
\text { Educação } \\
\text { Infantil }\end{array}$ \\
\hline
\end{tabular}

Fonte: Arquivos de pesquisa da autora desse artigo.

As licenciandas apresentavam entre 19 e 34 anos de idade na época das entrevistas, efetivadas após o estágio. Apenas uma delas não havia tido contato algum com a docência antes de estagiar. Já outras duas haviam exercido atividades de docência em programas governamentais ( PIBID $^{3}$ e Mais Educação ${ }^{4}$ ), sendo que uma atuou como catequista. Apenas Lara já lecionava na Educação Infantil.

\footnotetext{
${ }^{3}$ Programa Mais Educação: criado pelo Ministério da Educação do Brasil para melhorar a aprendizagem de crianças e jovens em Matemática e Língua Portuguesa por meio da ampliação da carga horária escolar. Mais informações vide http://portal.mec.gov.br/programa-mais-educacao/apresentacao.
} 
O quadro 2 traz informações sobre onde estagiou cada licencianda. Laura e Norma estagiaram em três turmas de sétimo ano, ao mesmo tempo, ao invés de escolherem duas turmas e estagiarem em uma turma por vez, replanejando o trabalho, conforme sugerido pelos professores de estágio. Elas justificaram que foi exigido pela escola que elas estagiassem nas três turmas ao mesmo tempo. Porém, Talita conseguiu estagiar somente junto a uma turma de sétimo ano, já que houve muitos imprevistos na escola e junto a seu professor regente, o que inviabilizou o trabalho com outra turma. Já Lara conseguiu desenvolver o estágio junto a duas turmas oitavo ano, seguindo a sugestão discutida na universidade, de estagiar primeiro com uma turma e depois com a outra, de modo a realizar uma investigação da própria prática e da aprendizagem dos estudantes.

\section{Quadro 2. Informações sobre o estágio das licenciandas}

\begin{tabular}{|l|l|l|}
\hline Licencianda & Local do Estágio & Séries em que estagiaram \\
\hline LAURA & Escola Municipal de Campo Formoso, Bahia & Três turmas de sétimo ano \\
\hline LARA & Escola Estadual de Senhor do Bonfim, Bahia & Duas turmas de oitavo ano \\
\hline NORMA & Escola Municipal de Campo Formoso, Bahia & Três turmas de sétimo ano \\
\hline TALITA & $\begin{array}{l}\text { Escola Municipal de Senhor do Bonfim, } \\
\text { Bahia }\end{array}$ & Uma turma de sétimo ano \\
\hline
\end{tabular}

Fonte: Arquivos de pesquisa da autora desse artigo.

No quadro 3 apresentamos algumas estratégias didáticas adotadas pelas estagiárias em busca de trabalhar de modo interdisciplinar. Trazemos as disciplinas envolvidas, conteúdos e temas transversais escolhidos pelas mesmas diante das necessidades dos estudantes ou da negociação com as escolas campo de estágio.

\footnotetext{
${ }^{4}$ PIBID - Programa Institucional de Bolsas de Iniciação à Docência: criado pelo Ministério da educação Brasileiro tendo em vista a inserção de licenciandos no universo escolar mediante o pagamento de bolsas de iniciação à docência. Busca o incentivo ao exercício do magistério e a melhoria da Educação Básica. Mais informações em http://portal.mec.gov.br/pibid.
} 
Quadro 3. Atividades desenvolvidas pelas licenciandas no estágio

\begin{tabular}{|c|c|c|c|c|}
\hline Licencianda(s) & $\begin{array}{l}\text { Disciplinas } \\
\text { envolvidas }\end{array}$ & Conteúdos & $\begin{array}{c}\text { Temas } \\
\text { transversais } \\
\text { envolvidos }\end{array}$ & $\begin{array}{l}\text { Estratégias didáticas utilizadas (junto a tentativas de articulações } \\
\text { interdisciplinares) }\end{array}$ \\
\hline $\begin{array}{l}\text { LAURA } \\
\text { E NORMA }\end{array}$ & $\begin{array}{l}\text { Biologia, } \\
\text { Química }\end{array}$ & $\begin{array}{c}\text { Fungos, } \\
\text { Bactérias, } \\
\text { Fermentação }\end{array}$ & $\begin{array}{c}\text { Meio } \\
\text { Ambiente e } \\
\text { Saúde }\end{array}$ & $\begin{array}{l}\text { Questionário de sondagem de saberes prévios sobre as bactérias, } \\
\text { observação e discussão da fermentação do leite, observação de } \\
\text { bactérias no leite (Lactobacilos e Estreptococos) e no suor do pé por } \\
\text { meio de microscópio, video (sobre bactérias), apresentação de slides, } \\
\text { discussão, elaboração de desenhos, jogo de adivinhação de imagens } \\
\text { sobre virus e bactérias, apresentação de peça teatral, observação do } \\
\text { processo de fermentação do pão com discussão da liberação do gás } \\
\text { carbônico, apresentação de paródia sobre funções, divisão e como } \\
\text { vivem os fungos, confecção de modelos de fungos e bactérias em } \\
\text { massa de modelar, dinâmica de sensibilidade. }\end{array}$ \\
\hline TALITA & $\begin{array}{l}\text { Biologia, } \\
\text { Lingua } \\
\text { Portuguesa }\end{array}$ & $\begin{array}{c}\text { Meio } \\
\text { Ambiente, } \\
\text { Ciclo de } \\
\text { vida, } \\
\text { Plantas, } \\
\text { Cadeia } \\
\text { Alimentar }\end{array}$ & $\begin{array}{c}\text { Meio } \\
\text { Ambiente, } \\
\text { Alimentação } \\
\text { saudável }\end{array}$ & $\begin{array}{l}\text { Questionário de sondagem de saberes prévios sobre seres produtores e } \\
\text { consumidores, Exibição de cartazes com ciclo de vida da borboleta, } \\
\text { discussão sobre ciclo de vida e importância dos alimentos como fonte } \\
\text { de energia, elaboração de desenho sobre ciclo de vida de algum animal, } \\
\text { comparação de plantas apresentadas em fotografias, exposição } \\
\text { participada, disputa de perguntas e respostas sobre plantas entre dois } \\
\text { grupos, discussão sobre a alimentação dos alunos, construção de } \\
\text { cardápio com alimentação saudável pelos alunos, vídeo, apresentação } \\
\text { de slides, produção textual sobre relações entre seres vivos por meio de } \\
\text { imagens, dinâmica da cadeia alimentar, observação de fungos em } \\
\text { alimentos e representação em forma de desenho. }\end{array}$ \\
\hline LARA & $\begin{array}{c}\text { Biologia, } \\
\text { Matemática, } \\
\text { Lingua } \\
\text { Portuguesa }\end{array}$ & $\begin{array}{c}\text { Sistema } \\
\text { Respiratório } \\
\text { Humano, } \\
\text { Virus }\end{array}$ & Saúde & $\begin{array}{l}\text { Questionário de sondagem de saberes prévios sobre respiração, } \\
\text { produção textual sobre como funciona a respiração humana (em forma } \\
\text { de poesia ou cordel), aula expositiva e dialógica, elaboração de } \\
\text { cartazes, observação de protótipo de pulmão, elaboração de mapa } \\
\text { conceitual, pesquisa sobre número de dos óbitos relacionados às } \\
\text { doenças respiratórias e registrados na Secretaria Municipal de Saúde } \\
\text { (SEMUS) da Cidade de Senhor do Bonfim, elaboração de gráficos, } \\
\text { vídeos sobre doenças relacionadas ao sistema respiratório, interação } \\
\text { com modelos didáticos e jogos computacionais sobre o sistema } \\
\text { respiratório humano - disponiveis no laboratório do corpo humano } \\
\text { (LAPSIV) da Univasf vídeo sobre vírus, produção de desenho e texto } \\
\text { envolvendo a temática Virus, observação de virus no microscópio, } \\
\text { pesquisa no computador sobre vírus, Levantamento de questões sobre } \\
\text { virus, produção de modelos didáticos de vírus. }\end{array}$ \\
\hline
\end{tabular}

Fonte: Arquivos de pesquisa da autora desse artigo.

A disciplina que foi escolhida por todas as participantes para a articulação interdisciplinar com outras matérias foi a Biologia, sendo que duas delas também escolheram trabalhar com a Língua Portuguesa.

Os dados coletados junto às licenciandas foram analisados e organizados em duas categorias: Concepções de Interdisciplinaridade e Resultados das Atividades Desenvolvidas.

Sobre a categoria Concepções de Interdisciplinaridade podemos aferir que nem todas licenciandas apresentaram concepções adequadas de interdisciplinaridade. De acordo com Laura, antes de ingressar na universidade, ela tinha a visão de que a disciplina Ciências era separada das demais matérias curriculares, que não havia relação 
entre elas. Para a mesma, Química, Física e Matemática não se relacionavam à disciplina Ciências. Entretanto, depois de estagiar na universidade, Laura modificou sua concepção sobre essa matéria, “(...) descobri que Ciências são todas essas disciplinas juntas" (LAURA, ENTREVISTA).

Laura demonstrou entender a interdisciplinaridade como sendo a ligação entre disciplinas: “(...) as disciplinas não são separadas como hoje são estabelecidas nas escolas, cada disciplina é uma matéria diferente, elas não são para serem assim, tem que ter uma interligação entre elas, acho que interdisciplinaridade é isso, a ligação entre as disciplinas" (LAURA, ENTREVISTA).

No estágio, Laura e Norma trabalharam os assuntos Vírus e Bactérias por meio de aulas expositivas, apresentação de vídeos e de paródia sobre fungos (que elas produziram), interpretação teatral e realização de experimentos (envolvendo o processo de fermentação do leite e da massa do pão). Elas buscaram apresentar os conteúdos por meio da diversificação de estratégias metodológicas, mais pautadas na exposição do assunto e na busca por alguma participação dos alunos.

Norma afirmou que ela e Laura conseguiram desenvolver práticas interdisciplinares no estágio. Para Norma, a interdisciplinaridade ocorre quando há um envolvimento entre as disciplinas - "interdisciplinaridade é o envolvimento das matérias que tem na grade curricular deles (dos alunos), não de formas separadas, mas juntas, e que cada uma se interligue com a outra" (NORMA, ENTREVISTA).

Em suas falas, tanto Laura quanto Norma mencionaram, de forma superficial, o sentido que atribuem à interdisciplinaridade. As duas trouxeram que a interdisciplinaridade se refere à ligação entre disciplinas, mas não explicaram como compreendem que isso acontece durante o processo de ensino e aprendizagem. Entretanto, suas práticas revelaram que as duas licenciandas não conseguiram efetuar um trabalho interdisciplinar no estágio e nem ao menos atingiram o nível de integração disciplinar.

É importante destacar que as ações de Norma e Laura foram pautadas basicamente em conteúdos curriculares referenciados à Biologia. Apesar de terem desenvolvido, junto aos estudantes, porções de massas de pão, estimulando-os a observarem o processo de fermentação e mencionarem durante a atividade acerca da liberação do gás carbônico, de fato não houve apresentação ou análise do processo. Laura deixou claro que não trabalharam, por exemplo, a expressão química desse fenômeno. Assim, não houve exploração de conteúdos químicos no decorrer do estágio 
delas. Não houve integração quanto a conteúdos, métodos, perguntas ou pressupostos entre a Biologia e a Química. Newelll e Green (1987) citam esse problema no que tange a estudos transdisciplinares. Ele aponta que em muitos casos uma disciplina exerce hegemonia e a outra não encontra um papel ativo no processo.

Para Spelt et al (2009) é difícil para os estudantes do ensino superior trabalharem além do contexto disciplinar: "Students have problems of working across disciplines, working in different disciplines, and synthesizing different disciplines" ${ }^{" 5}$. 266). E essa complicação dificulta o desenvolvimento do pensamento interdisciplinar neles, pois eles precisam aprender a superar diferenças entre as disciplinas, sejam epistemológicas, sejam nos discursos ou nas formas de ensino.

Norma deixou claro que o elemento principal que considerou no planejamento do ensino foi a elaboração de estratégias que pudessem ajudar a motivar os alunos:

Primeiro, eu pensei fazer coisas que chamassem atenção dos alunos, porque não adiantaria a gente trazer a interdisciplinaridade, trabalhar tema transversal e eles não quererem participar. E aí, nós imaginamos trazermos muitas brincadeiras, teatro, para chamar a atenção deles, e daí trabalhar a interdisciplinaridade. Levá-los a alguns laboratórios. Porque eles gostam, os alunos gostam muito desse negócio de laboratórios, estavam doidos para participar (NORMA, ENTREVISTA).

Para Norma, a interdisciplinaridade ocorre por meio da escolha da estratégia adequada, que pode ou não favorecer esse processo. Para a ela, o laboratório, por exemplo, pode ser considerado um espaço que trata muito da interdisciplinaridade. Conforme os relatos de Norma e de Laura, no laboratório elas apresentaram aos estudantes os instrumentos e os modelos didáticos disponíveis para que os mesmos conhecessem esse espaço na universidade e, inclusive, até tentaram desenvolver um experimento de análise de microrganismos, provenientes do suor coletado dos pés de alguns alunos, mas não foi possível fazê-lo. Entendemos que o elemento "atitude" do professor é imprescindível ao trabalho interdisciplinar, não somente o espaço profissional. Compreendemos que o espaço, por si só, não garante o exercício da interdisciplinaridade. O próprio termo "exercício da interdisciplinaridade" já deixa claro a necessidade de existência de uma ação, um fazer, que traz por si uma ideia de atitude de alguém, de um fazer interdisciplinar.

Para Newell e Green (1982), o problema da definição do que sejam os estudos interdisciplinares é algo que prejudica esse tipo de trabalho. A questão, já levantada anteriormente, é que os cursos disciplinares ou pluridisciplinares, mas autodenominados

\footnotetext{
5 Proposta de tradução da autora deste trabalho: "Os alunos têm problemas de trabalhar além das disciplinas, trabalhar em diferentes disciplinas e sintetizar diferentes disciplinas".
} 
como interdisciplinares, geram a banalização do termo. Para eles, geralmente essa má utilização do termo interdisciplinar em cursos que não o são, se deve mais à ignorância dos envolvidos do que por convicção ideológica. Também Fazenda (2011) entende que a falta de compreensão do que seja a interdisciplinaridade é um dos problemas do exercício dessa prática.

Para Norma, desenvolver um trabalho interdisciplinar não é fácil, mas é possível. Ela afirmou que realizar ações interdisciplinares no estágio até que foi fácil, já que um dos conteúdos trabalhados, Bactérias, envolveu a Biologia e a Química: “(...) usamos os laboratórios aqui na oficina com eles para fazerem observação, e lá na escola fizemos experiências químicas que foi a questão do iogurte, com a questão da fermentação" (NORMA, ENTREVISTA). Assim, Norma entende que o grau de dificuldade da ação interdisciplinar tem como um dos principais elementos as matérias envolvidas. Newelll e Green (1987) explicam que na realização da interdisciplinaridade é preciso conhecer as disciplinas envolvidas e também apontam que esse trabalho depende de quais disciplinas estão em questão e de como pode ocorrer a articulação de seus conteúdos, métodos, perspectivas ou das perguntas que fazem. Para esses autores, a Física e a Química, por exemplo, compartilham do mesmo método, hipotéticodedutivo, além delas fazerem perguntas sobre a mesma entidade teórica ou empírica. Entretanto, Newelll e Green (1987) esclarecem que as perguntas realizadas pelas duas áreas são diferentes.

Já a licencianda Talita parece estabelecer uma visão de interdisciplinaridade que leva em consideração as características semelhantes de diferentes disciplinas:

(...) na minha percepção sobre interdisciplinaridade, que é difícil de falar, eu sempre penso no questionamento de uma amiga minha, que chegou aqui no primeiro semestre. Ela chegou e me perguntou o quê que tinha haver Geografia com Matemática. Aí eu digo: mas se Geografia é política, e se na política lidamos com números - taxa de mortalidade infantil, taxas de pessoas idosas, nascimentos, mulheres, gestantes na idade da adolescência - isso é Matemática, isso é estatística, isso é interdisciplinaridade! (TALITA, ENTREVISTA)

Para Talita, as conexões entre a Geografia e a Matemática são naturais, como exemplifica no que tange à utilização de representação numérica ao se ensinar Geografia.

Sua visão de interdisciplinaridade também leva em conta as relações entre as disciplinas e a realidade contextual dos estudantes. Ela mencionou que seu professor de matemática da universidade a fez pensar sobre como essa disciplina está presente nas vidas das pessoas e as mesmas não percebem. É interessante observar a influência que o 
professor de Matemática da universidade exerceu sobre o pensamento de Talita. Isso nos leva a refletir sobre a importância que os professores formadores exercem nas práticas dos futuros professores de Ciências.

Além de tratar da facilidade em aproximar a Matemática da Geografia, Talita fez referência, inclusive, à ideia de que o desconhecimento de conceitos da Matemática influencia nas dificuldades de aprendizagem de alguns alunos em Ciências:

(...) no caso de Ciências, o aluno não sabe o que é unidade de vida, porque não sabe o que significa unidade. Isso é matemática, unidade de vida é célula, então a gente pode trabalhar Ciências assim, e pode trabalhar sim Matemática juntos, para que (o aluno) entenda, mas as pessoas não percebem (ENTREVISTA, TALITA).

No estágio, Talita propôs trabalhar sobre plantas, animais e suas interrelações, por meio do envolvimento da Biologia e da Língua Portuguesa. Ela conta que envolveu a Língua Portuguesa em duas atividades da sequência didática: numa delas pediu aos alunos que produzissem um cardápio alimentar que contivesse os alimentos que utilizavam com frequência em suas casas. A ideia era que os estudantes apresentassem esses cardápios e todos discutissem sobre alimentação saudável, além de analisarem aspectos gramaticais nos textos deles. Em outra atividade, essa estagiária propôs que os alunos completassem o desenho de uma cadeia alimentar, constituído por palavras, sílabas e imagens. Os alunos deveriam completar as sílabas faltantes para concluir o ciclo alimentar da atividade:

(...) era assim, por exemplo, se tivesse a palavra cobra aí a gente colocava a primeira sílaba da palavra cobra, por exemplo, com o desenho para formar do que era a cadeia alimentar, que a cobra poderia ser alimentada do sapo, o sapo se alimentaria do gafanhoto até chegar aos produtores, os vegetais (TALITA, ENTREVISTA).

Consideramos que Talita apresentou uma concepção mais aproximada de integração entre conteúdos da Biologia e da Língua Portuguesa. Isso porque, apesar de ter investido em assuntos mais relacionados à Biologia do que à Língua Portuguesa, ela demonstrou perceber que existem conexões entre as duas disciplinas, e até entre a Geografia e a Matemática (em exemplo anterior). Mas, também, ficou claro que a prática de Talita não foi interdisciplinar, pois para isso é preciso uma apropriação adequada dos conteúdos das disciplinas envolvidas e de seus pressupostos. Nesse caso, não ocorreu uma exploração adequada de conteúdos da Língua Portuguesa: no planejamento da construção do cardápio alimentar não houve mera menção a que aspectos gramaticais seriam levantados nos textos, ou se haveria alguma exploração disso. Inclusive, consideramos que a mera menção a um assunto durante uma aula não garante a aprendizagem dos estudantes. No que trata da atividade envolvendo a cadeia 
alimentar, o trabalho de completar o ciclo com base nas sílabas e figuras demonstrou ser muito fácil para os alunos, já que esses cursavam o sétimo ano. Consideramos que essa segunda atividade proposta pela licencianda não foi adequada aos estudantes envolvidos nessa oficina.

O trabalho interdisciplinar exige, além do conhecimento das disciplinas envolvidas, a criatividade do realizador. Isso porque, segundo Newelll e Green (1987) a integração disciplinar é uma atividade artesanal, exigindo um elemento criatividade que faz dela mais do que um ofício ou uma ciência. Enquanto que o conhecimento das matérias traz a segurança necessária à decisão de realizar esse trabalho, o elemento criatividade instiga o consecutor, o estimula, o desafia.

Assim como Talita, a licencianda Lara tentou realizar um trabalho interdisciplinar, propiciando conexões entre as disciplinas Biologia e Língua Portuguesa. Ela buscou articular o estudo da Respiração Humana (Biologia) com o assunto gêneros textuais (Língua Portuguesa), além de inserir aspectos de construção frasal no decorrer das aulas (Língua Portuguesa). É preciso destacar que o fato de Lara ser licencianda em Letras e também em Ciências da Natureza provavelmente a motivou na escolha das matérias. Além dessas, Lara também trabalhou com a Matemática, propiciando a organização das informações pesquisadas pelos estudantes e sua representação gráfica.

Logo no início do estágio Lara solicitou que os alunos produzissem um texto explicando como compreendiam o processo de respiração humana. Esse texto deveria ser produzido em um dos formatos: poema, poesia ou cordel. Entretanto, ela relatou que os estudantes do $8^{\mathrm{a}}$ ano A fizeram seus textos em forma de prosa, com linguagem denotativa, textos do tipo informativos. Quando ela aplicou a atividade com a turma do $8^{\mathrm{a}}$ ano B, Lara apresentou aos estudantes os três tipos de formatos de texto propostos, antes do início da atividade. Apesar disso, esses alunos se recusaram a utilizar esses formatos propostos e o fizeram no mesmo formato informativo que a outra turma, o que essa licencianda classificou como um padrão de comportamento resultante da falta de estímulo à escrita de textos em formatos diversos.

Ainda abordando o conteúdo Respiração Humana Lara solicitou que os alunos pesquisassem, na Secretaria de Saúde do município de Senhor do Bonfim, dados de óbitos relacionados a doenças respiratórias. Depois, foram criados gráficos com esses dados, de modo coletivo, utilizando como variáveis o sexo dos indivíduos e a ocorrência ou não de doenças respiratórias. 
Lara mencionou que sentiu que antes desse estágio os alunos haviam tido pouca ou nenhuma experiência interdisciplinar envolvendo as disciplinas Ciências e a Língua Portuguesa. A mesma percebeu isso num episódio em que um deles falou gramaticalmente de modo incorreto quando pediu para ir ao banheiro. Nessa ocasião, a estagiária aproveitou o ensejo e escreveu a frase dita no quadro, solicitando a ajuda de todos para corrigi-la. Em meio à situação, outro estudante questionou se estavam numa aula de Ciências ou de Português.

Apesar da falta de contato anterior dos alunos com a interdisciplinaridade a licencianda Lara conseguiu realizar um trabalho integrativo, pois sua ação relacionou assuntos de Biologia, de Língua Portuguesa e de Matemática, valorizando os conteúdos das três matérias. No que tange à Língua Portuguesa, houve ênfase ao conteúdo gêneros textuais. Já no que trata da Matemática, houve a construção e a interpretação de gráficos por meio de dados cotidianos, mas envolvendo as doenças respiratórias trabalhadas no tópico Respiração humana, proveniente da Biologia. No final das contas, foi necessário que os alunos adquirissem conhecimentos propostos pelas três matérias para que as atividades fossem realizadas.

De acordo com Newell e Green (1982), sabemos se uma questão é interdisciplinar ou não, observando se ela pode ou não ser respondida por meio de apenas uma disciplina. Para eles, um estudo interdisciplinar é iniciado por uma pergunta cujo escopo foge a uma única área. Depois, cada área do conhecimento deve tentar responder essa pergunta segundo um entendimento estreito de sua disciplina. E é no conjunto dessas respostas disciplinares estreitas que ocorre a integração. No caso de Lara, o conhecimento sobre como funciona a respiração humana, incluindo os números de óbitos relacionados a problemas respiratórios (no município onde os alunos estudam), foi construído por meio de conhecimentos provindos da Língua Portuguesa, da Biologia e da Matemática. Essa inter-relação entre conhecimentos de áreas diferentes ocorreu, ainda que a referida licencianda não tenha tido colaboração de outros professores nessas ações, mas partindo da sua próprio conhecimento nessas matérias e de sua atitude diante do desafio de trabalhar práticas interdisciplinares no ensino de ciências.

Para Lara, a interdisciplinaridade não envolve necessariamente outros professores, mas sim a relação entre conteúdos de matérias diversas, ainda que decorra no ensino de uma disciplina: “(...) a interdisciplinaridade é você enquanto, por exemplo, 
professor de Ciências, trazer elementos também das outras disciplinas que possam trabalhar ciências - mas eu posso envolver dentro daquilo que eu estou ensinando" (LARA, ENTREVISTA). Entretanto, Spelt et al (2009) destacam a importância das equipes de ensino focadas em interdisciplinaridade para facilitar a integração de disciplinas e da organização de um ambiente interdisciplinar mais seguro para propiciar a aprendizagem dos estudantes.

Acerca da categoria Resultados das Atividades Desenvolvidas, podemos observar que houve resultados positivos para todos os envolvidos. De acordo com Laura, o estágio trouxe ganhos de aprendizagem tanto para os alunos da escola campo quanto para as próprias estagiárias:

(...) nos manipulamos diante das dificuldades, solucionamos problemas de imediato, nos sentimos mais responsáveis por estarmos à frente de um projeto tão importante, e satisfeitas pelo bom resultado de ter ocorrido tudo nos conformes, principalmente de ver que valeu a pena todo o esforço quando pudemos observar que os alunos aprenderam bastante os conteúdos e gostaram de ter participado (LAURA, RELATÓRIO).

Laura afirmou que deve levar a aprendizagem adquirida no estágio tanto para sua vida profissional, quanto pessoal. Ela também assumiu que essa experiência a fez decidir ser professora, já que ela tinha dúvidas acerca disso. Essa licencianda acredita que conseguiu desenvolver um trabalho interdisciplinar envolvendo a Biologia e a Química, já que realizaram o experimento de fermentação do pão, ao mesmo tempo em que abordavam micro-organismos vivos. Quando questionada se trabalhou com a fórmula da fermentação, Laura justificou que esse assunto os alunos só devem trabalhar no nono ano, quando devem ver uma Química "mais avançada".

Para Laura, foi possível estimular o interesse da maioria dos alunos, mas não de todos, e seria preciso pensar num outro método através do qual conseguisse "passar o conteúdo" para esses também.

Do mesmo modo que Laura, Norma afirmou que a experiência no estágio a fez decidir ser professora. Ela disse que entrou na universidade sem esse desejo, mas algo no estágio a fez "abrir os olhos". Norma destaca que a parte mais importante desse processo foi verificar aquilo que já havia lido e discutido em classe, o bordão: "na prática a teoria é outra". Para ela, o professor planeja a aula de uma forma, mas a realidade traz circunstâncias diferentes. Além disso, Norma destacou que os alunos a ajudaram a aprender a ensinar, “(...) não como eles querem, mas da forma que eles aprendam" (NORMA, ENTREVISTA). 
Talita não apresentou considerações acerca dos resultados da aprendizagem dos alunos, mas focou na sua própria aprendizagem e em reflexões sobre os sentidos da docência. Ela acredita que a prática docente requer aprimoramento constante. Para ela, no processo formativo é preciso estar aberto a "novas formas de entender o mundo" e "fazer com que os alunos" entendam o "real sentido do acesso ao conhecimento, o qual deve ser não só transmitido, mas agregado ao sentido que se dá à vida e a tantas manifestações e criações humanas" (TALITA, RELATÓRIO). Ela destacou que temos a liberdade de sonhar e que não podemos perder isso, e a educação é "como uma mola que nos impulsiona para uma nova condição que nos dignifique e nos ajude a compreender a simples e perfeita beleza das coisas boas da vida" (id.).

Ao contrário de Talita, os resultados apresentados por Lara focalizaram a aprendizagem dos alunos, além de sua própria formação. Para ela, o período do estágio foi fundamental para seu desenvolvimento docente, pois:

(...) foi possível vivenciar uma experiência que permitiu atrelar a teoria à prática, obtendo inclusive resultados positivos, e isso não é outra coisa senão o resultado das atividades embasadas na interdisciplinaridade, transdisciplinaridade e nas reflexões das ações ali executadas (LARA, RELATÓRIO).

Lara explicou que a experiência de desenvolver ações com uma turma e ter a possibilidade de refletir sobre sua prática e rever esse trabalho antes de aplicá-lo com outra turma, possibilitou que ela modificasse seu planejamento, mudando metodologias um tanto "falhas". Esses resultados positivos foram percebidos pela mesma através da comparação das atividades que aplicou no início e ao final do estágio a cada turma junto a qual estagiou, envolvendo conteúdos trabalhados pela mesma. Para Lara, a análise do desenvolvimento da primeira turma nas aulas a fez utilizar com a segunda turma uma metodologia mais questionadora e experimental - através da qual privilegiou o levantamento de questões pelos alunos, com posterior criação de hipóteses e comprovação experimental. Lara não deixou claro quais foram essas questões, hipóteses ou experimentos desenvolvidos.

Para Carvalho (2002) é preciso que a universidade propicie aos licenciandos em estágio uma oportunidade de refletir na prática e sobre sua própria prática, o que Pimenta (2014) traz como pesquisa no estágio. Nesse processo de investigar suas ações de ensino e a aprendizagem de seus alunos o estagiário deixa de ser mero repetidor de comportamentos para ser "o pesquisador de sua própria prática pedagógica" (CARVALHO, 2002). 
Além disso, Lara também atribuiu o sucesso da experiência de ensino à busca pela interdisciplinaridade e mencionou até a transdisciplinaridade. Quando questionada sobre como compreende a transdisciplinaridade, Lara explicou que esta representa ir além das disciplinas, que para ela seria sair do âmbito das ciências e mesclar outros elementos e disciplinas.

Lara destacou lacunas entre a proposta explicitada no projeto Político Pedagógico da escola em que estagiou, e o que acontece na realidade. Ela também pontuou a falta de práticas interdisciplinares ou transdisciplinares na escola e ponderou que as falas dos docentes que presenciou apenas serviram para comprovar o que ela já havia percebido quanto à ausência de práticas interdisciplinares na escola.

\section{ALGUMAS CONSIDERAÇÕES}

Desenvolver um trabalho interdisciplinar, tanto no ensino superior quanto nas escolas, tem sido um grande desafio para os professores. Um dos grandes problemas relatados é a falta de entendimento acerca da interdisciplinaridade e sobre como desenvolver práticas interdisciplinares. Uma formação interdisciplinar seria então uma forma de incentivar esse tipo de trabalho.

A sondagem dos sentidos da interdisciplinaridade apresentados por quatro licenciandas em Ciências da Natureza nos fez constatar a necessidade de realizar essa formação interdisciplinar e trouxe alguns elementos que podem contribuir com a mesma. As licenciandas Laura, Norma e Talita demonstraram compreender a necessidade de integrar conteúdos, métodos ou pressupostos referentes a disciplinas diferentes. Elas acreditaram ter desenvolvido trabalhos interdisciplinares, apesar de não terem explorado as matérias pretendidas, se limitando a trabalhar conteúdos da Biologia em suas aulas de Ciências.

Já Lara, alcançou a integração interdisciplinar envolvendo as disciplinas Biologia, Língua Portuguesa e Matemática em suas aulas. Ela valorizou e explorou assuntos das três matérias em seu percurso, e esses conhecimentos foram indispensáveis ao alcance de seu propósito de que os alunos aprendessem acerca da Respiração Humana.

Acreditamos que a concepção mais adequada sobre interdisciplinaridade apresentada por Lara esteja relacionada tanto a sua formação em processo quanto a sua experiência docente. Enquanto estudante, tanto do curso de Ciências da Natureza quanto do curso de Letras, ela possui acesso a saberes dessas duas áreas, condição importante à 
efetivação interdisciplinar. Também, sua vivência como professora tenha auxiliado na elaboração de suas estratégias didáticas e em suas tomadas de decisão.

Sugerimos que sejam realizados estudos comparativos entre licenciandas com e sem experiência docente, para saber até que ponto essa experiência interfere no desenvolvimento do trabalho interdisciplinar. Além disso, também indicamos investigar a influência da formação do professor em mais de uma área do conhecimento para a efetividade da interdisciplinaridade no ensino.

\section{REFERÊNCIAS}

BOGDAN, R.; BIKLEN, S. Investigação qualitativa em educação: uma introdução à teoria e aos métodos. Porto, Portugal: Porto Editora, 1994.

BRASIL. Secretaria da Educação Média. Parâmetros curriculares nacionais: ensino médio/ Secretaria de Educação Média e Tecnológica. Brasília: MEC/SEFM, 2000. Disponível em http//portal.mec.gov.br/seb/arquivos/pdf/blegais.pdf. Acesso em 14, maio, 2018.

BRASIL. MEC.CNE.CEB. Diretrizes Curriculares Nacionais do Ensino Médio (DCNEM). Resolução nº 2, de 30 de janeiro. Brasília: MEC, SEB, DICEI, 2012.

BRASIL. MEC. CEB. DICEI. Diretrizes Curriculares Nacionais Gerais da Educação Básica. Brasília: MEC, SEB, DICEI, 2013.

CARVALHO, A. M. P. de. A pesquisa no ensino, sobre o ensino e sobre a reflexão dos professores sobre seus ensinos. Educação e Pesquisa, São Paulo, v. 28, n. 2, p. 57-67, jul./dez., 2002. Acesso em 14, maio, 2018, http://www.scielo.br/scielo.php?pid=S1517$97022002000200005 \&$ script $=$ sci abstract\&tlng $=$ pt.

FAZENDA, I. C. A. Formação de professores: dimensão interdisciplinar. Revista Brasileira de Formação de Professores - RBFP, v. 1, n. 1, p.103-109, Maio, 2009a.

FAZENDA, I. C. A. Interdisciplinaridade: definição, projeto, pesquisa. In: FAZENDA, Ivani (org). Práticas Interdisciplinares na escola. São Paulo: Cortez, 2009 b.

FAZENDA, I. C. A. Integração e Interdisciplinaridade no Ensino Brasileiro:

Efetividade ou ideoogia. São Paulo, SP: Edições Loyola, 2011.

FAZENDA, I. C. A. Interdisciplinaridade: História, teoria e pesquisa. Campinas, SP: Papirus, 2012a.

FAZENDA, I. C. A. A aquisição de uma formação interdisciplinar de professores. In: (org.). Didática e interdisciplinaridade. Campinas, SP: Papirus, 2012b.

JANTSCH, E. Vers l'Interdisciplinarité et la transdisciplinarité dans l'enseignement et l'innovation. in: L'Interdisciplinarité : Problemes d'Enseignement et de Recherche dans les Universités. Paris: CERI/OCDE, p.98-124, 1973. 
JAPIASSU, H. Interdisciplinaridade e Patologia do saber. Rio de Janeiro: Imago Editora, Ltda., 1976.

PEDROMO JUNIOR, J.; PUNTEL, R. L.; FOLMER, V. A percepção dos professores do Ensino Médio de uma escola da rede pública do município de Santa Maria/RS sobre ações interdisciplinares. Revista Ciências \& Ideias, v. 6, p. 13-28, 2015.

MACHADO, R. de S.; FERRARO, C. S.; LASCHUK, E. F. A importância do professor pesquisador: Uma reflexão envolvendo projetos temáticos desenvolvidos pelos bolsistas do PIBID PUC-RS. In: 34 EDEQ, 2014, Santa Cruz do Sul, 2014.

MORAES, R. Uma tempestade de luz: a compreensão possibilitada pela análise textual discursiva. Ciência \& Educação, v. 9, n. 2, p. 191-211, 2003.

MORAES, R.; GALIAZZI, Maria do Carmo. Análise textual discursiva: processo reconstrutivo de múltiplas faces. Ciência \& Educação, v. 12, n. 1, p. 117-128, 2006.

NEWELLL, W. H. GREEN, W. J. Defining and Teaching Interdisciplinary Studies. Heldred Publications: Washington, U.S.A, 1982.

PIATTI, T. M. ; MERCADO, L. P. L. ; SANTOS, A. A. ; MURTA, E. G. ; MONTE, G. M. ; CAVALCANTE, M. C. M. ; ABREU, N. G. . A formação do professor pesquisador do ensino médio: uma pesquisa ação em educação e saúde. Experiências em Ensino de Ciências (UFRGS), v. 3, p. 23-41, 2008.

PIMENTA, S. G.; LIMA, M. S. L. Estágio: diferentes concepções. In:

Estágio e docência. São Paulo: Cortez, 2014.

PRESTES, R. F.; MARQUES da SILVA. As contribuições do Educar pela Pesquisa no Estudo das Questões Energéticas. Experiências em Ensino de Ciências (UFRGS), v. 4, p. 7-20, 2009.

ROSA, M. I. de F. P. S.; SENE, I. P.; PARMA, M.; QUINTINO, T. C. de A. Formação de professores da área de ciências sob a perspectiva da investigação-ação. Revista Brasileira de Pesquisa em Educação em Ciências, v. 3, n. 1, p. 5-14, 2003.

SHULMAN, L. S. Those who understand: Knowledge growth in teaching. Educational Researcher, v. 15, n. 2, Feb, 4-14, 1986 (AERA Presidential Address). Disponível em http://links.jstor.org/sici?sici=0013189X\%28198602\%2915\%3A2\%3C4\%3ATWUKGI\%3E2.0.CO\%3B2-X. Acesso em 14, maio, 2018.

SPELT, E. J. H.; BIEMANS, H. J. A.; TOBI, H.; LUNING, P. A.; MULDER, M. Teaching and Learning in Interdisciplinary Higher Education: A Systematic Review. Educ. Psychol. Rev., 21, nov., 2009.

TARDIF, M. Os professores diante do saber: esboço de uma problemática do saber docente. In: Saberes docentes e formação profissional. Petrópolis, RJ: Vozes, 2007. 
THIESEN, Juares da Silva. A interdisciplinaridade como um movimento articulador no processo ensino-aprendizagem. Revista Brasileira de Educação, v. 13, n. 39, p.545554, dez., 2008.

UNIVERSIDADE FEDERAL DO VALE DO SÃO FRANCISCO. Projeto Pedagógico do Curso de Licenciatura em Ciências da Natureza. Senhor do Bonfim, Bahia, 2012. http://www.univasf.edu.br/ ccinat.bonfim/arquivos/ppc.pdf, acesso em 14, maio, 2018.

ZABALA, A. A função social do ensino e a concepção sobre os processos de aprendizagem: instrumentos de análise. In: A prática educativa . Porto Alegre: ArtMed, 1998. 